Western University

Scholarship@Western

FIMS Publications

Information \& Media Studies (FIMS) Faculty

2004

Health information seals of approval: What do they signify?

Jacquelyn Burkell

The University of Western Ontario, jburkell@uwo.ca

Follow this and additional works at: https://ir.lib.uwo.ca/fimspub

Part of the Library and Information Science Commons

Citation of this paper:

Burkell, J.A. (2004) Health information seals of approval: What do they signify? Information, Communication, and Society, special issue on e-health, 7(4), 491-509. 


\title{
Burkell - 1
}

Health Information Seals of Approval: What Do They Signify?

\author{
Jacquelyn Burkell, PhD \\ Assistant Professor \\ Faculty of Information and Media Studies \\ North Campus Building, Room 240 \\ The University of Western Ontario \\ London, Ontario, Canada N6A 5B7 \\ Email: jburkell@uwo.ca \\ Tel: 519-661-2111 ext 88506 \\ (address for correspondence)
}

Running Head: Burkell 


\title{
Burkell - 2
}

\begin{abstract}
Much of the health information available to consumers on the Internet is incomplete, out of date, and even inaccurate. Seals of approval or trustmarks have been suggested as a strategy to assist consumers to identify high quality information. Little is known, however, about how consumers interpret such seals. This study addresses this issue by examining assumptions about the quality criteria that are reflected by a seal of approval. This question is of particular importance because a wide variety of quality criteria have been suggested for online health information, including core aspects of quality such as accuracy, currency, and completeness, proxy indicators of quality such as the disclosure of commercial interests, and indicators that reflect the quality of the site or the interaction it affords, such as the availability of a search mechanism. The results of this study suggest that seals of approval are assumed to certify information quality primarily with respect to core quality indicators, aspects that subjects both consider to be important and feel relatively less able to evaluate for themselves (compared to their ability to rate proxy indicators of information or indicators of site or interaction quality). This assumption is largely inconsistent with practice: most seals of approval involve assessment of proxy indicators of information quality, rather than direct assessment of content. These results identify a problem that certification or accreditation bodies must address, since unless and until consumer expectations are congruent with evaluation practice, seals of approval seem to promise more than they deliver.
\end{abstract}




\section{Burkell - 3}

\section{Introduction}

A vast array of health-related information for consumers on virtually any topic is available on the Internet, and surveys of Internet users in the U.S. indicate that over half have gone online to seek health information (Rainie \& Packel, 2001; PEW Research Center, 2002). One significant concern of both providers and seekers of health information on the Internet is the relatively poor quality of that information, or at least the growing belief that where quality information does exist it will be impossible to find amidst lower quality, unfiltered information (Eysenbach, 2000a; Shon \& Musen, 1999). With regard to health information, this concern is well founded: it is widely documented that health information on the Internet is questionable in terms of coverage, accuracy, and currency (Bichakjian, et al. 2002; Eysenbach et al., 2002; Griffiths \& Christensen, 2000; Impicciatore et al., 1997; Latthe et al., 2000; Lissman \& Boehnlein, 2001; Pandolfini et al., 2000; Sandvik, 1999). Furthermore, although there is some indication that the quality of health information on the web has improved since the problem was first identified, quality control for online health information remains an issue of concern (Karp and Monroe, 2002: Pandolfini and Bonati, 2002).

Although some suggest there is "nothing radically different about information on the web" (Shepperd \& Charnock, 2002: p556; Risk \& Dzenowagis, 2001), most researchers agree that Internet information presents significant issues of quality control (Eysenbach \& Diegpen, 1998), particularly since research indicates that consumers use Internet health information to make important health care decisions. Internet health information leads consumers to ask questions of health care professionals and to seek second opinions (PEW Research Center, 2000; Potts \& Wyatt, 2002). Consumers use Internet health information for self-diagnosis and self-treatment (PEW Research Center, 2000; PEW Research Center, 2002); in fact, the use of this information often replaces or leads to the deferral of a visit to a health care professional (Nicholas et al., 2001: PEW Research Center, 2000; PEW Research Center, 2002). As a result, health care providers are concerned that low quality Internet health information could have negative consequences for consumer health and well-being. Although there are few documented cases of harm resulting from Internet health information (Smith, 2001b), such instances do exist (Kiley, 2002; Crocco et al., 2002), and a Database of Adverse Events Related to the Internet (DAERI) has recently been initiated to 


\section{Burkell - 4}

document cases of possible harm caused by health information obtained on the Internet (Eysenbach \& Köhler, 2002a).

Despite the general concern about the quality of health information found on the Internet, consumers themselves do surprisingly little to ensure the information they find is of high quality. Internet users only 'rarely' or 'occasionally' verify information obtained online, although reference information (and health information would clearly fall within this category) is more likely to be verified than commercial or entertainment information (Flanagin \& Metzger, 2000). Although consumers indicate that they examine source as a primary criterion when assessing credibility, in practice they do not verify sources or read disclaimers on the web sites they use: in fact, few even recall the sites from which they gather information (Eysenbach \& Köhler, 2002b). One possibility is that consumers access information from trusted sites, and therefore do not need to verify sources or information in every case. The data, however, suggest otherwise: most users find health information through an Internet search rather than being directed by a trusted source, and over half access information from unfamiliar web sites (Eysenbach \& Köhler, 2002b; Peterson et al., 2003; PEW Research Center, 2000). In practice, consumers explore the first few links provided by general search engines in response to suboptimal search queries (e.g., use of one search term when multiple terms would have been more effective: Eysenbach \& Köhler, 2002b). Consumers could use triangulation to identify high quality information, looking for information that is repeated on multiple sites. It appears, however, that this is another potential verification strategy that is not widely used, since fewer than one third consult four or more web sites for a given issue (Eysenbach \& Köhler, 2002b; PEW Research Center, 2000). Surprisingly, those consumers who do report verifying Internet information indicate that they are most likely to check if the information is current and complete (though it is unclear how they would make these judgments if they are unfamiliar with the content area), and less likely to check the author's qualifications or credentials, or check for external recommendations for the site, despite the fact that these latter factors would be easier for consumers to assess (Flanagin \& Metzger, 2000).

Obviously, consumers require assistance to identify high quality health information. Although it is important that consumers take a critical approach to all health information, independent evaluation can be of some assistance to help identify high quality information. One strategy that has been suggested is seals of approval, trustmarks, or certificates that can be displayed on health information sites indicating that the 


\section{Burkell - 5}

sites has met the standards of the body that grants the certification (Boyer et al., 1998; Eysenbach et al., 2001; Wathen \& Burkell, 2002). These quality indicators (which will be collectively termed 'seals of approval' throughout the remainder of this paper) have the advantage that they appear directly on websites

to which they are awarded, and thus their use as quality indicators requires no additional effort (as does the application of checklists of quality indicators such as the DISCERN checklist, available at http://www.discern.org.uk/) or specialized access (as do health information portals such as MedlinePlus, available at http://medlineplus.gov/) on the part of consumers.

Seals of approval have been used in the online context to identify sites that meet general quality criteria (e.g., the Good Housekeeping website certification:

http://magazines.ivillage.com/goodhousekeeping/consumer/institute/articles/0,284511_290570-3,00.html), and seals have also been used online for specific purposes such as tempering consumer privacy concerns (Miyazaki \& Krishnamurthy, 2002; Palmer et al., 2000). A number of seals of approval or trustmarks have been developed specifically for Internet health information. Some reflect self-reported voluntary compliance with a code of conduct (e.g., HONcode, administered by the Health on the Net Foundation, www.hon.ch), others involve third-party verification for which participants pay a fee (e.g., URAC Health Web Site Accreditation, administered by URAC, http://www.urac.org/), and still others involve a collaborative combination of self-report, consumer report, and expert evaluation and do not require a fee (e.g., the MEDcertain project, described at http://www.medcertain.org/). In every case, the goal is to identify Internet health information that meets quality criteria by means of a seal or label that appears on the website itself.

As consumers, we are not unfamiliar with this type of quality indicator: the 'Good Housekeeping Seal of Approval', for example, has been used to identify household items that meet the Good Housekeeping standards since 1910. Even in the relatively familiar domain of product advertising, however, the meaning of seals of approval is unclear and their interpretation by consumers is often inconsistent with the actual certification that is being offered. Parkinson (1975) found that advertising seals of approval were felt by consumers to represent "expertise", "impartiality" and "trustworthiness", but his results also indicated that consumers tend to attribute more meaning to such seals than is warranted. More recent research indicates that consumers misunderstand the degree to which even familiar seals of approval 


\section{Burkell - 6}

support factual, evaluative, and warranty claims (Beltramini \& Stafford, 1993; Laric \& Sarel, 1981). Nonetheless, in many studies seals of approval are shown to influence the perception of the product or service that is approved (Miyazaki \& Krishnamurthy, 2002; Laric \& Sarel, 1981; Cheskin Research, 2000;

Fogg et al., 2000: but see Beltramini \& Stafford, 1993 and Shon \& Musen, 2002 for results to the contrary). Thus, consumers appear to interpret seals of approval without fully understanding (or checking to find out) what the seal signifies or on what basis it is awarded.

One particular consequence is that consumers are likely to make assumptions about the criteria that determine the award of seals of approval. When the possible criteria are few and unequivocal, this presents no difficulty; but in the case of Internet health information a wide variety of indicators have been suggested as quality markers (Fallis \& Frické, 2002; Jadad \& Gagliardi, 1998; Kim et al., 1998; Winker et al., 2000). The 'JAMA benchmarks' (Silberg et al., 1997) are representative, and include display of authorship for medical content, source identification (attribution or references), date of last update, and disclosure of ownership, advertising policies, or conflicts of interest. The JAMA benchmarks demonstrate another important aspect of quality indicators for Internet information: the majority of these criteria represent proxy indicators of information quality (such as disclosure of authorship) rather than direct assessment of content. Although there are few formal evaluations of proxy indicators, those studies that have been completed suggest that these indicators bear at best a tentative relationship to information quality (Abbott, 2000; Fallis and Frické, 2002; Griffiths and Christensen, 2002; Martin-Facklam et al., 2002; Meric et al., 2002).

Thus, if consumers are going to guess about the criteria that are signified by a seal of approval (and previous research suggests they do guess), they have lots of options. Moreover, since the different criteria are not interchangeable (in that they reflect different aspects of quality), the choice is important. While proxy indicators such as author identification may well be important in their own right (Eysenbach, 2000b; Eysenbach, 2002), information that satisfies these proxy indicators is not necessarily accurate, complete, current, or unbiased. If consumers assume that seals reflect these core aspects of quality but evaluation instead assesses proxy indicators, there is potential for misinterpretation, and indeed overinterpretation, of the significance of seals of approval for Internet health information. 


\section{Burkell - 7}

As Delamothe (2000) points out, we know little about how consumers understand and use seals of approval in this context. In particular, we do not know what seals of approval are taken to signify: when a seal is displayed, what does it mean to a consumer? The research reviewed above suggests that, in general, seal interpretation is driven not by accurate knowledge of the certification process but rather by assumptions regarding the evaluation that underlies the award. This study explores these assumptions with respect to seals of approval for Internet health information. In particular, the study addresses the following questions: which quality criteria do consumers consider to be important, how able do they feel to evaluate the criteria for themselves, and what are their assumptions about the criteria that would be evaluated in order to assign a seal of approval to an Internet health information site?

Method

Identification of Quality Criteria

An initial list of 24 quality indicators for Internet information was developed based on a review by Falshaw (2002), who assembled indicators reported in the published literature in library and information science and medicine as well as online Internet information evaluation guidelines (Alexander \& Tate, 1996; Barry \& Schamber, 1998; Beck, 2002; Block, 2001; Collins, 1996; Connell \& Tipple, 1999; Everhart, 1996; Fallis \& Frické, 2002; Grassian, 2000; Hawkins, 1999; Jadad \& Gagliardi, 1998; Joseph, 1999; Kapoun, 1998; Lopez, 1998; Minkel, 2000; Schrock, 1998; Schrock, 1999; Smith, 1997; Smith, 2001 a; Tillman, 2001; Waller 2001). In order to limit the criteria to a reasonable number, similar criteria were grouped together under a single identifier. Thus, for example, all criteria relating to the disclosure of commercial interests were grouped under "Website is free of commercial interests OR commercial interests are declared". In addition, the list was limited to criteria relating to content, and criteria related to other aspects of service delivery (e.g., privacy protection) were eliminated from the list. The resulting criteria tended to fall into two groups: proxy indicators of information quality (such as lack of spelling, grammar, and typographical errors), and indicators that reflect the quality of the site or the quality of interaction (such as the availability of a search function). None of the criteria gathered from Falshaw (2002) involved direct 


\section{Burkell - 8}

assessment of the quality of information, and (as reported above) proxy indicators are not strongly predictive of information quality. As a result, the 24 criteria identified by Falshaw (2002) were augmented by four core aspects of information quality: accuracy, currency, completeness, and lack of bias. The final list of 28 indicators, separated into the three types (core quality criteria, proxy quality indicators, and site or interaction quality criteria), is presented below (see Table 1).

Insert Table 1 about here

Procedure

Participants were a convenience sample of first year undergraduate students enrolled in an introductory media studies course. The researcher distributed the questionnaires at the beginning of a class session, and students returned the completed questionnaires. A total of 64 questionnaires were returned, of which 3 were unusable because subjects failed to complete all ratings for one or more questions (e.g., all 'ability to rank' ratings were left blank), leaving 61 usable responses.

The data were collected by means of a paper and pencil questionnaire. The questionnaire included of three types of ratings for each of the 28 quality criteria described above. Participants were asked rate each quality criterion in response to the following instructions: 1) identify how important you think each criterion is for choosing health information on the web; 2) indicate how confident you are that you could evaluate each criterion for choosing health information on the web $;^{1}$ 3) identify how important you think each criterion would be in determining whether a site merits a 'seal of approval'. Before rating the contribution of the criteria to a 'seal of approval', subjects were first shown examples of (hypothetical) seals that might be used to identify health information that met quality criteria (see Figure 2). All ratings were on a scale of 10, with 1 representing the lowest level of the rating (not at all important, certain you could not evaluate yourself, or very unlikely to contribute to a 'seal of approval'), and 10 representing the 


\section{Burkell - 9}

highest level of the rating (very important, certain you could evaluate yourself, or very likely to contribute to a 'seal of approval').

Insert Figure 1 about here

Subjects completed each type of rating with respect to every criterion before moving on to the next type of rating. Each subject received the rating tasks in the same order: 1) importance; 2) ability to evaluate ${ }^{2} 3$ ) expected contribution to 'seal of approval'. One random order of the criteria was identified and the criteria were presented in this same order for all rating tasks. The entire package of ratings took approximately 20 minutes to complete.

Results

Table 2 shows, for each quality indicator, the average score (across subjects) for each rating tasks (importance (abbreviated as IMP), ability to rate (abbreviated as ABIL), and expected contribution to a seal of approval certification (abbreviated as SEAL)). For each rating task, the items that ranked in the top five with respect to average rating are identified by table entries in bold. The average scores for IMP ranged from a low of 5.4 (for 'Web site is aesthetically pleasing') to a high of 9.6 (for 'Information is accurate, reliable, and error-free'). ABIL scores ranged from a low of 4.3 (for 'Information has been reviewed for accuracy') to a high of 8.2 (for 'Web site has no spelling, grammatical, or typographical errors',

'Information is free of cost', and 'Web site is easy to navigate'). The scores for SEAL ranged from a low of 5.5 (for 'Web site is aesthetically pleasing') to a high of 9.5 (for 'Information is accurate, reliable, and error-free). 
Insert Table 2 about here

A quick perusal of the table reveals a strong similarity between IMP and SEAL ratings, and an almost reverse ordering for ABIL. The same five items receive the highest average ratings for both IMP and SEAL, while four of these items were among the five lowest ratings on the ABIL task. The pattern of correlations between the types of ratings supports these initial impressions. Pairwise correlations revealed a strong positive relationship between IMP and SEAL $(\mathrm{r}(28)=.834, \mathrm{p}<.001)$, a strong negative relationship between ABIL and SEAL (r(28)=-.794, p<.001), and a moderate negative relationship between IMP and ABIL $(r(28)=-.597, p<.01)$. According to these results, the same criteria tend to be identified as important and expected to contribute to awarding a seal of approval; furthermore, the criteria that receive high ratings for each of these qualities tend to be the core quality criteria of accuracy, completely, and currency (lack of bias, the fourth core quality criterion, also receives high ratings on both scales, but does not rank within the top five). In contrast, respondents are quite uncertain of their own ability to rate information according to these core quality criteria, and instead indicate more confidence in rating proxy quality indicators or criteria relating to site or interaction quality.

The results of an ANOVA comparing average scores for the three types of quality indicators (information quality (abbreviated INF), proxy indicators of information quality (abbreviated PROX), and indicators of site or interaction quality (abbreviated SITE)) across the three rating tasks (IMP, ABIL, SEAL) are largely consistent with this interpretation. The ANOVA results reveal a significant main effect of rating task $(\mathrm{F}(1,59)=29.17, \mathrm{p}<.001)^{3}$, a significant mail effect of type of quality indicator $(\mathrm{F}(2,118)=16.99, \mathrm{p}<.001)$, and a significant interaction of rating task and indicator type $(\mathrm{F}(1,59)=99.32$, $\mathrm{p}<.001)$. Further analysis of the interaction was carried out using simple main effects and subsequent tests of means with Bonferroni adjustment for multiple comparisons. For the IMP task, there were significant differences among the three types of indicators $(\mathrm{F}(2,120)=97.78, \mathrm{p}<.001)$. For this task, INF indicators received higher ratings than either PROX or SITE indicators, which did not differ significantly from each other (means of 8.9 for INF indicators, 7.2 for PROX indicators, and 6.9 for SITE indicators, $\mathrm{t}(61)=10.88$, 


\section{Burkell - 11}

$\mathrm{p}<.001$ for the comparison of INF and PROX, $\mathrm{t}(61)=11.21, \mathrm{p}<.001$ for the comparison of INF and SITE, and $\mathrm{t}(61)=2.08$, n.s. for the comparison of PROX and SITE). For the ABIL task there were also significant differences across the three types of criteria $(F(1,59)=49.22, \mathrm{p}<.001)$. All three pairwise comparisons were significant, but the direction of the differences was reversed from that observed for the IMP task, with SITE criteria rated higher than PROX criteria, which were in turn rated higher than INF criteria (means of 5.1 for INF, 66. for PROX, and 7.5 for SITE, $\mathrm{t}(60)=5.47, \mathrm{p}<.001$ for the comparison of INF and PROX, $t(61)=7.76, p<.001$ for the comparison of INF and SITE, and $t(60)=6.63, p<.001$ for the comparison of PROX and SITE). For the SEAL task, there were significant differences among the three types of ratings $(\mathrm{F}(1,60)=78.01, \mathrm{p}<.001)$, and all three pairwise comparisons were significant, with INF criteria rated higher than PROX criteria, which were in turn rated higher than SITE criteria (means of 8.9, 7.5, and 6.2 respectively, $\mathrm{t}(61)=7.72, \mathrm{p}<001$ for the comparison of INF and PROX, $\mathrm{t}(61)=10.93, \mathrm{p}<.001$ for the comparison of INF and SITE, and $\mathrm{t}(61)=6.05, \mathrm{p}<.001$ for the comparison of PROX and SITE). The results of this analysis are consistent with expectations. Indicators that directly reflect information quality (INF indicators) are rated as most important and most likely to contribute to a seal of approval, while subjects indicate that they feel least able to assess these same indicators.

Finally, a regression analysis was used to examine the degree to which SEAL ratings were determined by IMP and ABIL. The results for the full model (both variables entered) reveals that both IMP and ABIL contribute significantly to the prediction ( $t=5.47, \mathrm{p}<.001$ for IMP, $\mathrm{t}=-4.52, \mathrm{p}<.001$ for ABIL), and together these two predictors account for $82 \%$ of the variance in SEAL ratings $(\mathrm{R}=.912, \mathrm{~F}(2,25)=61.97$, $\mathrm{p}<.001$, adjusted $\mathrm{R}^{2}=.819$ ). Furthermore, after accounting for IMP, the partial correlation of ABIL with SEAL is negative (partial correlation=-.67, $\mathrm{p}<.001$ ). In other words, subjects think that seals of approval reflect first those qualities they consider to be important, and second those criteria they feel less able to evaluate for themselves.

\section{Conclusion}

When a consumer sees a seal of approval on a health information website, what does it signify? The results of this study suggest that seals of approval are assumed to identify information that meets core quality criteria such as accuracy, currency, completeness, and lack of bias. In the eyes of study participants, 


\section{Burkell - 12}

a seal of approval indicates that the information meets quality criteria they consider to be important, and those they feel less able to rate for themselves.

Seals of approval are intended as information interfaces - tools that assist consumers with the difficult task of sorting information 'wheat' from 'chaff'. A good interface is transparent: that is, it does precisely what the user expects it to do (Mountford, 1990). Interfaces that are transparent allow us to do our work (in this case, finding high quality health information) easily and effectively. The data reported in this paper provide insight into expectations regarding the meaning of seals of approval leads. These results lead to the natural question: do seals of approval meet expectations? In other words, are seals of approval transparent interfaces?

Typically, the answer is 'no'. HONcode, URAC Health Web Site Accreditation, and MedCertain are designed to certify web health web sites with respect to both the information they provide and the practices (such as privacy protection) associated with the provision of that information. With respect to information quality, these seals of approval tend to rely on proxy indicators of quality rather than direct assessment of content. Thus, the HONcode code of conduct indicates that web sites displaying the HONcode label should comply with standards that include

- Indication of authorship

- Indication of author credentials

- Disclaimer with respect to information use

- Date of last modification and creation date indicated

- Citation of sources for factual information

- Disclosure of commercial interests

- Contact information for author

- Indication of site sponsorship

Although URAC explicitly notes that their accreditation program "is not designed to guarantee a minimum level of quality for health content" (URAC Health Web Site Standards, p 7), it seems likely that consumers would interpret their "Health Site Accreditation" as implying that the site provides trustworthy information, and their criteria include a number of standards that can be interpreted as proxy measures of information quality, including 
- The web site does not make claims of therapeutic benefit without reasonable support

- Name of author and information source is provided

- Date content was developed and/or date of last update displayed

- $\quad$ References to information sources provided

Of the three seals discussed here, only the MedCertain uses criteria involve any direct quality assessment, and that is only for the third level of their proposed three-level trustmark system. In the MedCertain approach, first level trustmarks are awarded on the basis of provider claims with respect to proxy measures of information quality, and second level trustmarks are awarded on the basis of consumer evaluation of these same criteria. It is only at the third level of certification that expert assessment of information content is provided. Given this difference between consumer expectation and actual practice, we can only conclude that seals of approval are not transparent interfaces.

This result must be considered with care, since consumer expectations should not necessarily be taken as a practice prescription for seals of approval. There are very good reasons why an accreditation body would choose to certify with respect to proxy indicators rather than through objective assessment of content (Carrol et al., 2002; Eysenbach, 2000b; Eysenbach, 2002; Purcell et al., 2002). Not least among these is the problem that, for most if not all health information, there exists no gold standard that can be used to determine whether the information is in some absolute sense correct. It is possible, therefore, that bringing consumer expectations and the actual significance of seals of approval to congruence is a goal better realized by correcting consumer assumptions than by changing the evaluation practices associated with seals of approval. The data reported here do not point to the solution, but only identify the problem to be solved: as it stands, seals of approval do not deliver what they seem to promise.

As a final note, it is important to address some possible criticisms of this study. First, respondents were a convenience sample of undergraduate students, and thus it cannot be claimed that the sample is formally representative of the population of those seeking health information online. Although this limits the generalizability of the results, the focus of this study is differences between criteria and relationships between the various types of rating tasks, and this type of result is less likely to be influenced by sampling bias (Burkell, 2003). Furthermore, the students who participated in the study are, if anything, more sophisticated than the general public with respect to Internet use and the evaluation of online material, since 


\section{Burkell - 14}

a course on this particular issue forms part of their required curriculum. Second, the study examined expectations regarding hypothetical, rather than actual, seals of approval. The responses, therefore, cannot be based on any actual knowledge of the process or criteria for assigning the seals, and it is arguable that understanding of the criteria used to grant a specific real seal of approval (e.g., the HONcode label) would differ from expectations of these generic and hypothetical seals. There are at least two reasons, however, to believe that the results would not be very different if real seals of approval were used. First, even those seals of approval that are most widely used appear on relatively few web sites (e.g., in a recent study, Fallis and Frické (2002) found that only 16\% of the health information sites they reviewed displayed the HONcode label), and thus consumers are unlikely to have extensive experience with any seal of approval that would lead to more accurate perception of the conditions under which the seal is granted. Second, earlier research suggests that consumers over-interpret even the most familiar of quality seals (the Good Housekeeping Seal of Approval), suggesting that their interpretation of seals of approval is based more on assumption than on actual knowledge. These results, therefore, are definitely reflective of consumer assumptions regarding new or unknown seals, and likely reflect their assumptions regarding even wellestablished seals of approval for Internet health information.

\section{Acknowledgements:}

The author would like to acknowledge the valuable contribution of an anonymous reviewer, whose thoughtful comments significantly improved the quality of this paper. 


\section{Burkell - 15}

References

Abbott, V.P. (2000) 'Web page quality: Can we measure it and what do we find? A report of exploratory findings', Journal of Public Health Medicine, vol. 22, no.2, pp. 191-197.

Alexander, J. and Tate, M. A. (1996) 'Evaluating web resources', Wolfgram Memorial Library, Widener University, [online] Available at: http://www2.widener.edu/Wolfgram-MemorialLibrary/webevaluation/webeval.htm (May 13, 2004).

Barry, C. L. and Schamber, L. (1998) 'User’s criteria for relevance evaluation: A cross-situational comparison’ Information Processing and Management, vol. 34, no.2/3, pp. 219-336.

Beck, S. E. (2002) 'The good, the bad \& the ugly: or, why it's a good idea to evaluate web sources', New Mexico State University Library, [online] Available at: http://lib.nmsu.edu/instruction/evalcrit.html. (May 13, 2004).

Beltramini, R.F. \& Stafford, E.R. (1993) 'Comprehension and perceived believability of seals of approval information in advertising'. Journal of Advertising, vol. 23, no.3, pp. 3-13.

Bichakjian CK, Schwartz JL, Wang TS, Hall JM, Johnson TM, Biermann JS. (2002) ‘Melanoma information on the internet: often incomplete--a public health opportunity?', Journal of Clinical Oncology, vol. 20, no.1, pp 134-141.

Block, M. (2001) 'Consumer health information on the net', Library Journal, vol. 126, no. 8(May 12001 Suppl.), pp. 21-24.

Boyer, C., Selby, M., \& Appel, R.D. (1998) 'The Health On The Net code Of conduct for medical and health web sites', Medinfo, vol. 9 (Pt2), pp. 1163-1166.

Burkell, J.A. (2003) 'The dilemma of survey nonresponse', Library and Information Science Research, vol. 25, pp. 239-263.

Carrol, A.E., Saluja, A., \& Tarczy-Hornoch, P. (2002) 'Consumer health information on the internet', Journal of the American Medial Informatics Association, vol. 9, no.4, pp 402-405.

Cheskin Research (2000) 'Trust in the wired Americas', [online] Available at: http://www.cheskin.com/think/studies/trustIIrpt.pdf (13 May 13 2004).

Collins, B. R. (1996) ‘Beyond cruising: Reviewing', Library Journal, vol. 121, no. 3, pp. 122-124. 
Connell, T. H. and Tipple, J. E. (1999) 'Testing the accuracy of information on the World Wide Web using the Alta Vista search engine', Reference and User Services Quarterly, vol. 38, no. 4, pp. 360-368.

Crocco, A.G., Villasis-Keever, M., \& Jadad, A.R. (2002) 'Analysis of cases of harm associated with use of health information on the internet', Journal of the American Medical Association, vol. 287, no. 21, pp. 2869-2871.

Delamothe, T. (2000) 'Quality of websites: kitemarking in the west wind', British Medical Journal, vol. 321, no. 7265, pp. 843-844.

Everhart, N. (1996) 'Web page evaluation worksheet', St. John's University, Division of Library and Information Science, Jamaica, NY, [online] Available at: http://www.duke.edu/ de1/evaluate.html (May 13, 2004).

Eysenbach, G. (2000a) 'Consumer health informatics’, British Medical Journal, vol. 320, pp. 1713-1716.

Eysenbach, G. (2000b) 'Heidelberg consensus recommendations on trustmarks', Journal of Medical Internet Research, vol. 2 (suppl 2), pp. e12.

Eysenbach, G. (2002) 'Infodemiology: the epidemiology of (mis)information', American Medical Journal, vol. 113 , pp. $763-765$.

Eysenbach, G., \& Diegpen, T.L. (1998) 'Towards quality management of medical information on the internet: evaluation, labeling, and filtering of information', British Medical Journal, vol. 317, pp. 1496-1500.

Eysenbach, G., \& Köhler, C. (2002a) 'Does the internet harm health? database of adverse events related to the internet has been set up', British Medical Journal, vol. 324, no. 7331, pp. 239.

Eysenbach, G., \& Köhler, C. (2002b) 'How do consumers search for and appraise health information on the world wide web? Qualitative study using focus groups, usability tests, and in-depth interviews', British Medical Journal, vol. 324, pp. 573-577.

Eysenbach, G., Powell, J., Kuss, O., \& Sa, E. (2002) 'Empirical studies assessing the quality of health information for consumers on the world wide web', Journal of the American Medical Association, vol. 287 , no. 20 , pp. 2691-2700. 


\section{Burkell - 17}

Eysenbach, G., Köhler, C., Yihune, G., Lampe, K, Cross, P., \& Brickley, D. (2001) ‘A framework for improving the quality of health information on the world-wide-web and bettering public (e-) health: the MedcCertain approach', Medinfo, vol. 10(Pt2), pp 1450-1454.

Fallis, D., \& Frické, M. (2002) 'Indicators of accuracy of consumer health information on the internet: a study of indicators relating to information for managing fever in children in the home', Journal of the American Medical Informatics Association, vol. 9, no. 1, pp. 73-79.

Falshaw, D. (2002) 'Assessing the credibility of online information', Paper submitted in fulfillment of the requirements for LIS 698, Faculty of Information and Media Studies, University of Western Ontario.

Flanagin, A.J., \& Metzger, M.J. (2000) 'Internet use in the contemporary media environment', Human Communication Research, vol. 27, no. 1, pp. 153-181.

Fogg B.J., Marshall J., Laraki O., Osipovich A., Varma C, Fang N., Paul V., Rangnekar A., Shon J., Swani P., Treinen M. (2000) 'Elements that affect web credibility: early results from a self-report study', CHI proceedings, pp 287-288, [online] Available at: http://delivery.acm.org/10.1145/640000/633460/p287fogg.pdf?key $1=633460 \&$ key $2=7743284801 \&$ coll=portal $\& \mathrm{dl}=\mathrm{ACM} \& \mathrm{CFID}=21624097 \&$ CFTOKE $\underline{\mathrm{N}=31027292}$ (May 16,2004).

Grassian, E. (2000) 'Thinking critically about World Wide Web resources', UCLA College Library, [online] Available at: http://www.library.ucla.edu/libraries/college/help/critical/ (May13, 2004).

Griffiths, K.M. \& Christensen, J. (2000) 'Quality of web based information on treatment of depression: cross sectional survey’, British Medical Journal, vol. 321, pp. 1511-1155.

Hawkins, D. T. (1999) 'What is credible information?', Online, vol. 23, no. 5, pp. 86-89.

Impicciatore, P., Pandolfini, C., Casella, N., \& Bonati, M. (1997) 'Reliability of health information for the public on the world wide web: Systematic survey of advice on managing fever in children at home', British Medical Journal, vol. 314, pp. 1875-1879.

Jadad, A.R., \& Gagliardi, A. (1998) 'Rating health information on the internet: navigating to knowledge or to Babel?', Journal of the American Medical Association, vol. 279, no. 8, pp. 611-614. 


\section{Burkell - 18}

Joseph, L. C. (1999) 'WWW CyberGuide Ratings for Content Evaluation', [online] Available at: http://www.cyberbee.com/guides.html (May 13, 2004).

Kapoun, J. (1998) ‘Teaching undergrads Web evaluation’, College and Research library News, vol. 59, no. 7, pp. $522-523$.

Karp, S., Monroe, A.F. (2002) 'Quality of health information on the internet: caveat emptor still rules', Managed Care Quarterly, vol. 10, no. 2, pp. 3-8.

Kiley, R. (2002) 'Does the internet harm health? Some evidence does exist that the internet harms health', British Medical Journal, vol. 323, no. 7331, pp. 328-329.

Kim, P., Eng, R.T., Deering, M.J., \& Maxfield. A. (1998) 'Published criteria for evaluating health related web sites: review', British Medical Journal, vol. 318, pp. 647-649.

Kunst, H., Groot, D., Latthe, P., Latthe, M., \& Khan, K.S. (2002) 'Accuracy of information on apparently credible websites: survey of five common health topics', British Medical Journal, vol. 321, pp. 581-582.

Laric, M.V., \& Sarel, D. (1981) 'Consumer (mis)perceptions and usage of third party certification marks, 1972 and 1980: did public policy have an effect?', Journal of Marketing, vol. 45, no. 3, pp. 135142.

Latthe, P.M., Latthe, M., \& Khan, K.S. (2000) 'Quality of medical information about menorrhagia on the world wide web', British Journal of Obstetrics and Gynecology, vol. 107, no. 1, pp. 39-43.

Lissman, T.L., \& Boehnlein, J.K. (2001) ‘A critical review of internet information about depression’, Psychiatric Services, vol. 52, no. 8, pp. 1046-1050.

Lopez, A. (1998) 'Nurse directories on: The nurse friendly web site evaluation resources', Nursefriendly, Inc., [online] Available at: http://www.nursefriendly.com/nursing/linksections/webevaluation.htm. May 13, 2004).

Martin-Facklam, M., Kostrzewa, M., Martin, P., \& Haefeli, W.E. (2003) 'Quality of drug information on the World Wide Web and strategies to improve pages with poor information quality. An intervention study on pages about sildenafil', British Journal of Clinical Pharmacology, vol. 57, no. 1 , pp. $80-85$. 


\section{Burkell - 19}

Meric, F., Bernstam, E.V., Mirza, N.Q., Hunt, K.K., Ames, F.C., Ross, M.I., Kuerer, H.M., Pollock, R.E., Musen, M.A., \& Singletary, S.E. (2002) 'Breast cancer on the world wide web: Cross sectional survey of quality of information and popularity of websites', British Medical Journal, vol. 321, pp. $577-581$.

Minkel, W. (2000) 'No, it’s not all true', Library Journal Net Connect, vol. Summer 2000, pp. 33-34.

Miyazaki, A.D., \& Krishnamurthy, S. (2002) 'Internet seals of approval: effects on online privacy policies and consumer perceptions', The Journal of Consumer Affairs, vol. 36, no. 1, pp. 28-49.

Mountford, S. J. (1990) 'Tools and techniques for creative design', in The Art of Human-Computer Interface Design, ed. B. Laurel, Addison Wesley, Readings, Massachusetts, pp.17-30.

Nicholas, D., Huntington, P., Williams, P., \& Blackburn, P. (2001) 'Digital health information provision and health outcomes', Journal of Information Science, vol. 27, no. 4, pp. 265-276.

Palmer, J.W., Bailey, J.P., \& Faraj, S. (2000) 'The role of intermediaries in the development of trust on the Www: the use and prominence of trusted third parties and privacy statements', Journal of Computer-Medicated Communication, vol.5, no. 3., [online] Available at: http://www.ascusc.org/jcmc/vol5/issue3/palmer.html (May 13, 2004).

Pandolfini, C., Impicciatore, P., \& Bonati, M. (2000) 'Parents on the web: risks for quality management of cough in children', Pediatrics, vol. 105, no. 1, pp. e1., [online] Available at: http://pediatrics.aappublications.org/cgi/reprint/105/1/e1.pdf?ijkey=5e1c638a9d1380bbaacea199a b421eac292c8202 (May 13, 2004).

Pandolfini, C., \& Bonati, M. (2002) 'Follow up of quality of public oriented health information on the World Wide Web: systematic re-evaluation', British Medical Journal, vol. 324, pp. 582-583.

Parkinson, T.L. (1975) 'The role of seals and certifications of approval in consumer decision making', Journal of Consumer Affairs, vol. 9, pp. 1-16.

Peterson, G., Aslani, P. and Williams, K.A. (2003) 'How do consumers search for and appraise information on medicines on the Internet? A qualitative study using focus groups', Journal of Medical Internet Research, vol. 5, no. 4, e33, [online] Available at: http://www.jmir.org/2003/4/e33/index.htm,

(May 14, 2003). 
PEW Research Center (2000) 'The online health care revolution: how the web helps americans take better care of themselves', [online] Available at: http://www.PEWinternet.org (May 13, 2004).

PEW Research Center (2002) 'Vital decisions: how internet users decide what information to trust when they or their loved ones are sick', [online] Available at: http://www.PEWinternet.org (May 13, 2004).

Potts, H.W.W. \& Wyatt, J.C. (2002) 'Survey of doctors' experience of patients using the internet', Journal of Medical Internet Research, vol. 4, no. 1, pp. e5, [online] Available at: http://www.jmir.org/2002/1/e5/index.htm (May 13, 2004).

Purcell, G.P., Wilson, P., \& Delamothe, T. (2002) 'The quality of health information on the internet', British Medical Journal, vol. 324, pp. 557-558.

Rainie, Lee, \& Packel, Dan (2001) 'More online, doing more. PEW internet project: internet tracking report', [online] Available at: http://www.PEWinternet.org/reports/pdfs/PIP_Changing_Population.pdf (May 13, 2004)

Risk, A., \& Dzenowagis, J. (2001) 'Review of internet health information quality initiatives', Journal of Medical Internet Research, vol. 3, no. 4, pp. e28, [online] Available at: http://www.jmir.org/2001/4/e28/index.htm (May 16, 2004).

Sandvik, H. (1999) 'Health information and interaction on the internet: a survey of female urinary incontinence', British Medical Journal, vol. 319, no. 7201, pp. 29-32.

Schrock, K. (1999) 'Teaching media literacy in the age of the Internet', Classroom Connect, December 1998/January 1999, [online] Available: http://school.discovery.com/schrockguide/pdf/weval.pdf. (May 13, 2004).

Schrock, K. (1998). Separating the wheat from the chaff: How to tell the good sites from the bad. Internet Trend Watch for Libraries, [online] Available at: http://school.discovery.com/schrockguide/chaff.html. (May 13, 2004).

Shepperd, S. \& Charnock, D. (2002) ‘Against internet exceptionalism: there’s nothing radically different about information on the web', British Medical Journal, vol. 324, no. 9, pp. 556-557.

Shon, J., Marshall, J., \& Musen, M.A. (2000) 'The impact of displayed awards on the credibility and retention of web site information', Proceedings of the AMIA Annual Symposium, pp. 794-798. 


\section{Burkell - 21}

Shon, J. \& Musen, M. A. (1999) 'The low availability of metadata elements for evaluating the quality of medical information on the World Wide Web', Proceedings of the AMIA Annual Symposium, pp. 945-949.

Silberg, W.M., Lundberg, G.D., \& Musacchio, R.A. (1997) 'Assessing, controlling , and assuring the quality of medical information on the internet: caveat lector et viewor - let the reader and viewer beware', Journal of the American Medical Association, vol. 277, pp. 1244-1245.

Smith, A. G. (1997) Testing the surf: Criteria for evaluating Internet information resources. The PublicAccess Computer Systems Review, vol. 8, no. 3, [online] Available at: http://info.lib.uh.edu/pr/v8/n3/smit8n3.html. (May 13, 2004).

Smith, A. G. (2001a). Evaluation of information sources: The World-Wide Web virtual library, [online] Available at: http://www.vuw.ac.nz/ agsmith/evaln/evaln.htm. (May 13, 2004.

Smith, R. (2001b) 'Almost no evidence exists that the internet harms health', British Medical Journal, vol. 323, no. 7314 , pp. 651 .

Tillman, H. N. (2001). Evaluating quality on the net. Babson College, Babson Park, Massachusetts, Available at: http://www.hopetillman.com/findqual.html (May 13, 2004).

Waller, R. (2001). Evaluate your website: Sixty ticks for a good website. Richard Waller Website Creation, Training and Consultancy, [online] Available at: http://www.waller.co.uk/eval.htm (May 13, 2004).

Wathen, C. N. and Burkell, J. (2002) 'Believe it or not: Factors influencing credibility on the web', Journal of the American Society of Information Science and Technology, vol. 53, no. 2, pp. 134144.

Winker, M.A., Flanagin, A., Chi-Lum, B., White, J., Andrews, K, Kennett, R.L., DeAngelis, C.D., \& Musacchio, R.A. (2000) 'Guidelines for medical and health information sites on the internet: principles governing AMA web sites', Journal of the American Medical Association, vol. 283, no. 12, pp. $1600-1606$.

Date: November 17, 2003

Words: 4342 
Burkell - 22

Figure 1: Seals of Approval

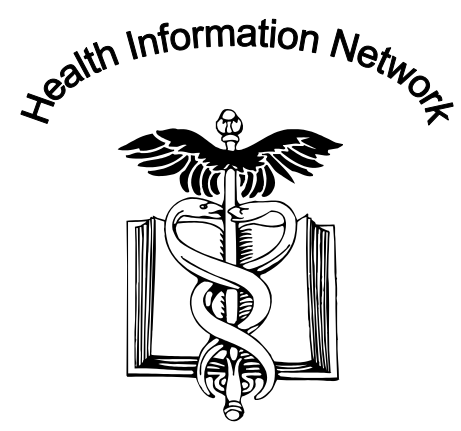

Seal of Approval

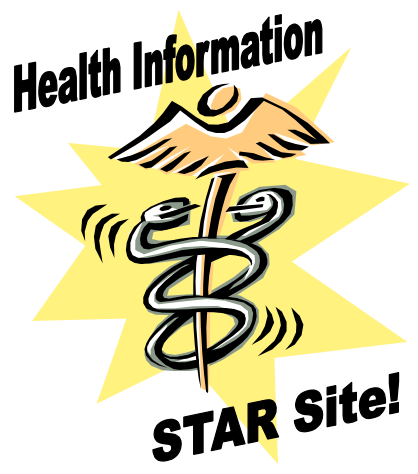


Burkell - 23

\section{Table 1: Quality Criteria}

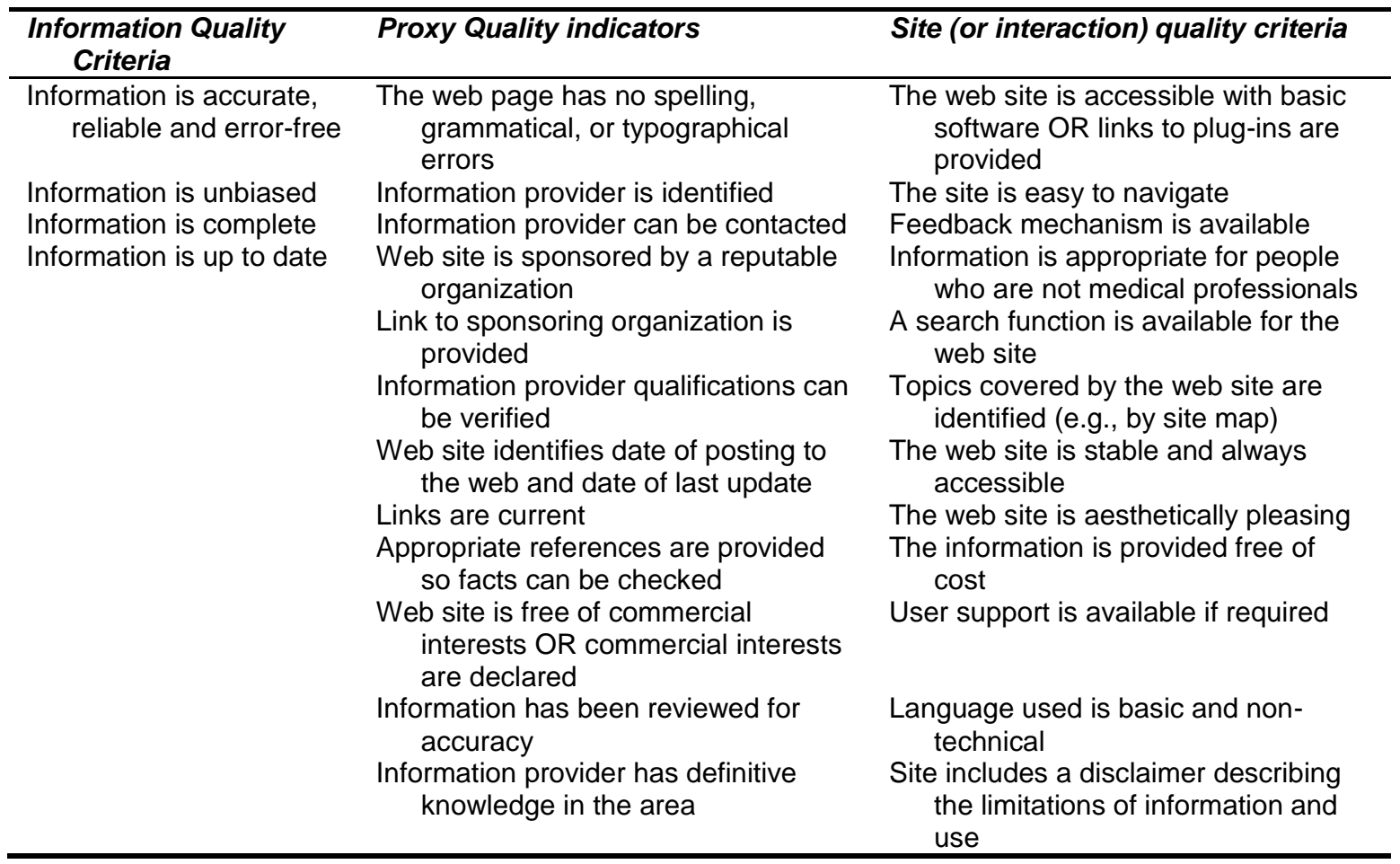


Table 2: Average Ratings for Quality Criteria (the five highest rated criteria for each task are presented in bold)

\begin{tabular}{|c|c|c|c|}
\hline Criterion & & Rating & \\
\hline & Importance & Ability & Seal \\
\hline Information is accurate, reliable, and error-free & 9.6 & 5.0 & 9.5 \\
\hline Information is complete & 8.7 & 4.6 & 9.1 \\
\hline Information provider has definitive knowledge in the area & 9.1 & 4.6 & 9.0 \\
\hline Information has been reviewed for accuracy & 8.7 & 4.3 & 9.0 \\
\hline Information is up-to-date & 9.0 & 5.6 & 8.9 \\
\hline Information is unbiased & 8.4 & 5.3 & 7.9 \\
\hline Appropriate references are provided so facts can be checked & 7.8 & 6.7 & 7.9 \\
\hline Information provider qualifications can be verified & 7.1 & 5.1 & 7.9 \\
\hline Information provider is identified & 7.5 & 7.2 & 7.7 \\
\hline Web site links are current & 7.5 & 6.8 & 7.6 \\
\hline Web site has no spelling, grammatical, or typographical errors & 7.0 & 8.2 & 7.6 \\
\hline Web site is sponsored by a reputable organization & 6.6 & 5.7 & 7.4 \\
\hline Web site is stable and always accessible & 7.7 & 7.3 & 7.1 \\
\hline Web site identifies date of posting to the web and date of last update & 7.0 & 7.6 & 7.1 \\
\hline $\begin{array}{l}\text { Information is appropriate for people who are not medical } \\
\text { professionals }\end{array}$ & 7.8 & 7.5 & 6.9 \\
\hline $\begin{array}{l}\text { Web site includes a disclaimer describing the limitations of } \\
\text { information and use }\end{array}$ & 6.5 & 6.3 & 6.8 \\
\hline Web site is easy to navigate & 7.4 & 8.2 & 6.5 \\
\hline Language used is basic and non-technical & 7.3 & 8.1 & 6.4 \\
\hline Information is provided free of cost & 8.4 & 7.9 & 6.3 \\
\hline Information provider can be contacted & 6.0 & 7.7 & 6.3 \\
\hline Web site has a link to sponsoring organization & 5.7 & 7.3 & 6.3 \\
\hline Web site has feedback mechanism available & 5.8 & 7.1 & 6.1 \\
\hline $\begin{array}{l}\text { Web site is free of commercial interests OR commercial interests are } \\
\text { declared }\end{array}$ & 6.0 & 7.3 & 6.0 \\
\hline Web site has search function & 7.1 & 7.9 & 5.8 \\
\hline Web site includes map or other identification of the topics covered & 6.4 & 7.5 & 5.8 \\
\hline Web site provides user support if required & 6.2 & 6.6 & 5.7 \\
\hline $\begin{array}{l}\text { Web site is accessible with basic software OR links to required plug- } \\
\text { ins are provided }\end{array}$ & 6.3 & 7.3 & 5.6 \\
\hline Web site is aesthetically pleasing & 5.4 & 8.2 & 5.5 \\
\hline
\end{tabular}


${ }^{1}$ Subjects also rated a fourth aspect: the likelihood that they would use the criterion in evaluating health information. This task, however, proved somewhat difficult for subjects and as a result the ratings were difficult to interpret. In light of these issues, this rating task was eliminated from further analyses.

2 The 'likelihood of use' task was the third in the package, appearing between ratings of ability to evaluate and contribution to seals of approval.

${ }^{3}$ The analysis of variance results reveal that the sphericity assumption is violated for the main effect of rating task and the interaction of task and indictor type. Therefore, these two effects are evaluated tieh reduced degrees of freedom, using the Lower Bound correction. 